\title{
Estudo comparativo da biocompatibilidade da submucosa intestinal porcina e pericárdio bovino usados como enxertos na veia cava de cães ${ }^{1}$
}

\author{
Comparative study of the biocompatibility of the porcine intestinal submucosa and \\ bovine pericardium used as grafts in the inferior cava vein of dogs
}

\author{
Fernando Hintz Greca ${ }^{2}$, Lucia de Noronha ${ }^{3}$, Francisco Diniz Afonso da Costa ${ }^{4}, Z_{\text {Zacarias Alves de Souza Filho }}^{5}$, Andréa \\ Thomaz Soccol $^{6}$, André Néry Feres ${ }^{6}$, Jõao Ricardo Duda ${ }^{6}$, Eduardo Adams ${ }^{7}$ \\ 1. Trabalho Realizado na Disciplina de Técnica Operatória da Faculdade de Medicina da Pontifícia Universidade do Paraná. \\ 2. Professor Titular, Coordenador da Disciplina de Técnica Operatória e Cirurgia Experimental da PUCPR.. \\ 3. Professora, Doutora em Patologia da PUCPR e UFPR. \\ 4. Professor Titular da Disciplina de Técnica Operatória e Cirurgia Experimental da PUCPR. \\ 5. Professor Titular da Disciplina de Cirurgia Geral da UFPR e Professor Titular da Disciplina de Técnica Operatória e Cirurgia Experimental \\ da PUC-PR. Doutor em Clínica Cirúrgica. \\ 6. Alunos de iniciação científica da Disciplina de Técnica Operatória da PUCPR. \\ 7. Cirurgião Cardiovascular.
}

\begin{abstract}
RESUM0
Objetivo: Comparar a biocompatibilidade entre submucosa de intestino delgado (SID) porcino e o pericárdio bovino como enxerto no reparo de lesões criadas na veia cava inferior de cães. Métodos: Dezesseis cães foram submetidos a laparotomia. Após a abertura da cavidade abdominal a veia cava foi identificada e em seguida procedeu-se com a retirada de um segmento elíptico de 1,5X3cm de sua parede anterior. Em 8 animais o defeito foi reparado com SID porcino (grupo A) e nos 8 animais restantes o defeito foi reparado com pericárdio bovino (grupo B).No $30^{\circ}$ dia de P.O. realizou-se uma ultra-sonografia e a eutanásia foi realizada no $40^{\circ}$ dia de pós-operatório. Resultados: Observou-se estenose da veia cava em 1 cão do grupo do grupo A e em 2 animais do grupo B além de trombose em 1 cão desse mesmo grupo. A análise microscópica revelou um processo inflamatório crônico moderado em ambos os grupos. A endotelização do enxerto, regeneração de fibras musculares lisas e depósito de colágeno também foi similar nos 2 grupos estudados. Conclusão: A SID provou ser um excelente substrato para a regeneração vascular quando implantado em veia cava superior, contudo os resultados encontrados não diferem daqueles observados com o uso de pericárdio bovino
\end{abstract}

Descritores: Bioenxertos. Submucosa de Intestino Delgado Porcino. Pericárdio Bovino.

\begin{abstract}
Purpose: To compare the biocompatibility of the bovine pericardium and the small intestine submucosa (SIS) when used to repair a created defect in the inferior vena cava of dogs. Methods: Sixteen male mongrel dogs were submitted to a midline laparotomy incision. An elliptical segment (1,5 X 3,0 cm) of the inferior vena cava, below the renal veins, was excised. In 8 dogs, the A group, a patch of porcine small bowel submucosa was used to repair the defect. In the 8 remaining dogs, the B group, a bovine pericardium was implanted in the vena cava. On the $30^{\text {th }}$ post-operative day an ultrasound was performed in order to identify stenosis. The euthanasia was accomplished in the $40^{\text {th }}$ post-operative day. Stenosis of the vein was observed in 1 dog of A group and in 2 of the B group. Results: Partial thrombosis with collateral circulation was evidenced in 1 dog of the bovine pericardium group. A moderated chronic inflammatory process was evidenced in both groups. Microscopic evaluation, regarding endothelization of the implant, collagen deposition, smooth muscle growth, was similar in both groups. Conclusion: SIS proved to be a functional graft patch for possessing local vena cava remodeling and its biocompatibility was similar to bovine pericardium.
\end{abstract}

Key words: Biomaterial. Small Intestine Submucosa. Bovine Pericardium.

\section{Introdução}

As lesões de veia cava, resultantes de trauma ou conseqüentes a exérese de neoplasias infiltrativas, requerem muitas vezes o uso de enxertos vasculares. A baixa velocidade de fluxo, a baixa pressão e a tendência das paredes venosas de colabarem estão entre os fatores responsáveis pela trombose precoce. Os enxertos sintéticos, usados com sucesso no sistema arterial, não apresentam os mesmos resultados no sistema venoso. As próteses de PTFE apresentam trombose precoce em 18\% dos casos e a proliferação intimal é responsável pela obstrução de $40 \%$ da luz do vaso. A veia safena autóloga, comumente usada como um enxerto valioso nem sempre é apropriado ou disponível ${ }^{1}$. Apesar dos avanços da cirurgia vascular nas últimas décadas, não contamos ainda com um enxerto ideal 
que preencha todos critérios de biocompatibilidade tais como: resistência a infecção, facilidade no manuseio, disponibilidade em diversos tamanhos e que apresente potencialidade de crescimento, quando usada em cirurgia pediátrica ${ }^{2}$. Um biomaterial derivado da submucosa de intestino delgado porcino tem sido usado para desenvolverse uma nova matriz biológica. Após sua utilização em estudos pré-clínicos que avaliaram sua biocompatibilidade em várias espécies testadas, evidenciou-se que a SID é capaz de remodelar-se gradualmente, adquirindo semelhanças que a tornam indistinguível do tecido implantado. A SIS é um biomaterial que apresenta resistência à infecção bacteriana e não desenvolve reação de rejeição no hospedeiro, uma vez que sua resposta imune é mediada pelos linfócitos Th2. Graças a sua matriz tridimensional e a presença de glicoproteínas, proteoglicanos, glicosaminoglicanos, a SID tem a propriedade de fixar células na matriz. Além do mais os fatores de crescimento em sua superfície, estimulam a migração, fixação e diferenciação celular ${ }^{3,4,5}$. Outra alternativa, no que concerne a bioenxertos, seria o pericárdio bovino que foi introduzido por Ionescu em 1977 na cirurgia cardiovascular e por Braile na confecção de próteses valvares. Serve para substituto de paredes atrial e ventricular, remendo arterial e venoso assim como reconstituição do saco pericárdico ${ }^{6}$. Apesar de sua razoável biocompatibilidade, o pericárdio bovino é capaz de retrairse, calcificar-se, formar aneurismas.e induzir resposta imune no hospedeiro ${ }^{7,8}$. Visto que podemos contar com dois bioenxertos para reparos da veia cava, fomos motivados a fazer um estudo comparativo, cujo objetivo primordial foi comparar a biocompatibilidade da SID e do pericárdio bovino quando utilizados para reparar lesões induzidas na veia cava inferior de cães.

\section{Métodos}

Na elaboração deste estudo foram obedecidas as normas do Colégio Brasileiro de Experimentação Animal (COBEA). Para o desenvolvimento da pesquisa foram utilizados 16 cães mestiços, pesando entre 8 e $15 \mathrm{Kg}$, provenientes do Biotério da Pontifícia Universidade Católica do Paraná. Os animais foram mantidos em condição de temperatura e luminosidade naturais e alimentados com ração canina padrão comercial e água potável em regime livre. O jejum foi instituído nas 12 horas precedentes às intervenções cirúrgicas. Uma hora antes da operação foi realizada tricotomia e limpeza mecânica da região anterior do abdômen. A medicação pré-anestésica utilizada foi composta de sulfato de atropina $(0,05 \mathrm{mg} / \mathrm{kg})$ e midazolan (0,2 mg[kg) por via endovenosa. A anti-sepsia da região operatória foi feita com polivinilpirrolidona-1\% de iodoativado. Foi então realizada, incisão abdominal mediana supra e infra-umbilical de aproximadamente $15 \mathrm{~cm}$ de extensão. Após a abertura da cavidade abdominal identificou-se a veia cava inferior e as veias renais. Dois minutos antes da colocação dos clampes vasculares, procedeu-se com a anticoagulação, utilizando-se sulfato de heparina na dosagem de $30 \mathrm{u} / \mathrm{kg}$ de peso. Após a colocação dos clampes vasculares, realizou-se a exérese de um segmento elíptico de 1,5 X 3,0 cm da parede anterior da veia cava inferior, $2 \mathrm{~cm}$ abaixo das veias renais. Realizou-se o reparo da parede da veia com SID em 8 cães no grupo A e com pericárdio bovino em 8 cães no grupo B. O pericárdio bovino foi obtido da indústria cardiopróteses sendo conservada em glutaraldeído. Para a obtenção da submucosa de intestino delgado, foi mobilizado um segmento de jejuno suíno situado a $20 \mathrm{~cm}$ da flexura duodeno-jejunal, sendo então realizada enterectomia de $10 \mathrm{~cm}$ a partir desse ponto. Após a obtenção de segmento de jejuno o seu mesentério foi removido. O segmento intestinal foi então invertido de modo que a mucosa ficasse voltada para fora. Esta foi removida através de raspagem com bisturi, sendo a lâmina posicionada em sentido transversal ao maior eixo do intestino. Foi desfeita a inversão do segmento intestinal e o extrato seromuscular foi removido pela mesma técnica. $\mathrm{O}$ folheto de submucosa obtido foi colocado em solução de neomicina a $10 \%$. Tanto o enxerto de pericárdio bovino quanto o de submucosa de intestino delgado porcino foi suturado na veia cava com fio de polipropileno vascular 5-0 (Figura 1).

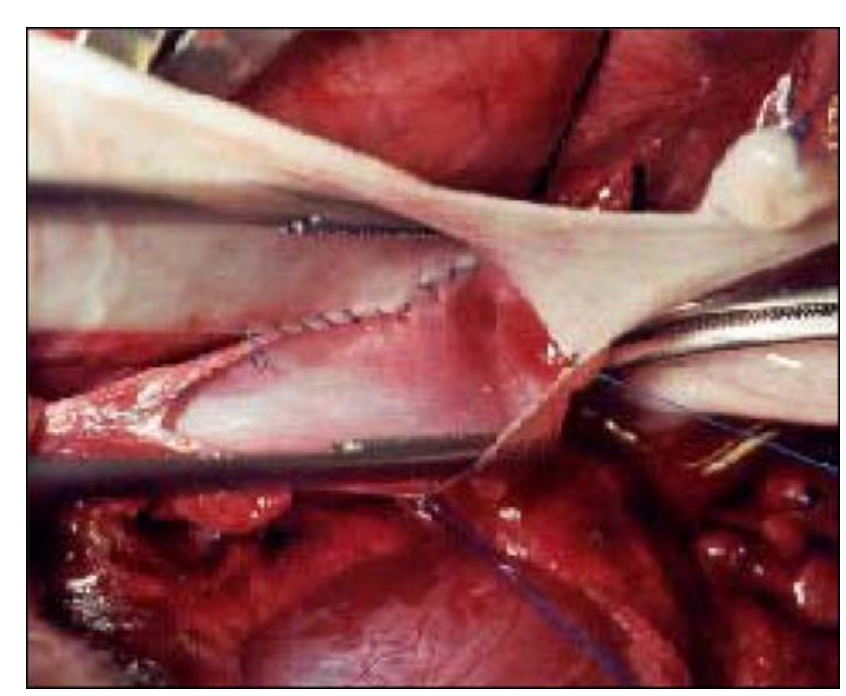

FIGURA 1 - Retalho de submucosa sendo suturado na veia cava inferior no defeito elíptico criado em sua parede anterior.

Após o término da sutura vascular, os clampes foram abertos (o cranial inicialmente e o caudal posteriormente) e reverteu-se a anticoagulação, com protamina na concentração de $0,01 \mathrm{ml} / \mathrm{kg}^{2}$. Observou-se o enchimento sangüíneo para verificação da patência da veia e a impermeabilidade da sutura. Até a síntese da parede abdominal, todos os animais desse experimento permaneceram, sem sangramento no local enxertado e com patência vascular preservada. Durante 40 dias, os cães foram acompanhados clinicamente no biotério da universidade. No $30^{\circ}$ dia de P.O., todos os animais foram submetidos a exame ultrassonográfico do abdômen, cujo objetivo foi analisar possíveis alterações como estenoses, calcificações, dilatações aneurismáticas, trombos ou circulação colateral na veia cava inferior. Através desse exame, realizou-se uma análise clínica objetiva mediante a mensuração dos diâmetros da veia cava infra-renal. No $40^{\circ}$ dia de pós-operatório os cães foram submetidos a uma segunda lapartomia, através da cicatriz cirúrgica anterior, para a 
ressecção do segmento da veia cava inferior, abrangendo o enxerto e uma porção de $1 \mathrm{~cm}$ proximal e distal ao enxerto. Após a eutanásia, as peças cirúrgicas foram removidas e analisadas. A análise macroscópica consistiu na avaliação da presença de calcificações, estenoses, dilatações aneurismáticas, trombos e circulação colateral. Na análise objetiva foi mensurado o diâmetro em três segmentos do vaso: no local da enxertia e nos segmentos adjacentes, $(1 \mathrm{~cm}$, proximal e distal ao enxerto) . As porções distais e proximais foram consideradas áreas referenciais. Prosseguiu-se com a divisão da veia cava em duas porções: (1) área do enxerto; (2) áreas referenciais proximais e distais, sendo que o experimento contou com 16 espécimes, divididos em 48 segmentos, sendo 24 provenientes da área do enxerto e 24 das áreas referenciais proximais e distais. As peças foram fixadas em formol a $5 \%$, sendo posteriormente processadas conforme as técnicas histológicas convencionais e coradas com hematoxilinaeosina e Sirius Red para realização da análise microscópica. Na análise microscópica subjetiva, as lâminas coradas com hematoxilina-eosina foram avaliadas quanto a presença ou a ausência de endotélio, músculo liso, fibrose e processo inflamatório. A análise objetiva, por sua vez, consistiu na quantificação do processo inflamatório agudo ou crônico através de uma tabela objetiva de escores. Para a construção desta tabela foram escolhidas as variáveis congestão, edema e neutrófilos para caracterizar o processo inflamatório agudo. Presença de tecido de granulação, fibrose e células mononucleares foram escolhidas para caracterizar fase inflamatória crônica. Tanto as variáveis da fase inflamatória crônica como da fase aguda foram quantificadas em: 0 =ausente, 1 =discreto, $2=$ =moderado, $3=$ =acentuado, sendo que aquelas da fase aguda receberam sinal negativo e as da fase crônica sinal positivo. A somatória de todas as variáveis permitiu a realização de um escore inflamatório. Os escores localizados entre $-9 \mathrm{a}-2$ foram considerados da fase aguda, entre -1 a +1 foram considerados ausência de processo inflamatório e entre +2 a +9 , fase inflamatória crônica. Para complementar a análise objetiva, avaliou-se a percentagem ocupado por colágeno e músculo liso nas lâminas coradas com Sirus Red. Em cada área (enxerto ou referencial) foram realizadas 6 medidas em 6 campos microscópicos diferentes. Para essa avaliação utilizou-se de um microscópio da marca Olympus ${ }^{\circledR}$, com aumento de 100 vezes, acoplado a uma câmera de vídeo Sony . O software escolhido para a morfometria de área foi o “Image Pro-Plus”. Para a análise estatística da avaliação macroscópica utilizou-se o teste não-paramétrico de Wilcoxon. Na análise microscópica subjetiva de presença de endotélio, músculo, colágeno e de processo inflamatório adotou-se o teste Exato de Fisher. Para avaliação morfométrica de músculo e colágeno adotouse o teste não-paramétrico de Mann-Whitney, esse último também foi utilizada para avaliação dos escores microscópicos, considerando-se um valor de $\mathrm{p}<0,05$ estatisticamente significante.

\section{Resultados}

\section{Análise Clínica:}

Todos os 16 cães evoluíram satisfatoriamente durante os 40 dias de observação pós-operatória. O estudo ultrassonográfico não revelou calcificações ou aneurismas em nenhum dos animais dos grupos estudados. Observouse estenose ultrassonográfica em 1 cão do grupo A (submucosa) e em 2 cães do grupo B (pericárdio bovino). Nesse último verificou-se a presença de circulação colateral em um cão e trombose parcial em outro.

\section{Análise Macroscópica:}

Não foram observadas calcificações nem dilatações aneurismáticas. Observou-se estenose da veia cava em um cão do grupo A. Já em contrapartida no grupo B foi observado aumento da circulação colateral em dois cães (cães 13 e 16). Estenose foi observada em três cães do grupo B (cães 9, 10 e 15). A veia cava foi medida em seu diâmetro no enxerto e nas porções distal do mesmo. Os resultados obtidos estão contidos na Tabela 1.

TABELA 1 - Diâmetro da veia cava inferior no local do enxerto e $1 \mathrm{~cm}$ a montante do mesmo.

\begin{tabular}{llccccc}
\hline Diâmetro & \multicolumn{2}{c}{ Valor } & \multicolumn{2}{c}{ Pericárdio } & Valor de \\
da Veia & \multicolumn{2}{c}{ SID } & dep & & p \\
Cava & No local & $1 \mathrm{~cm}$ distal & & No local & $1 \mathrm{~cm}$ distal & \\
Inferior & do enxerto & do enxerto & & do enxerto & do enxerto & \\
\hline Média $\pm \mathrm{DP}$ & $1,15 \pm 0,30$ & $1.09 \pm 0,26$ & 0,325 & $0,81 \pm 0,33$ & $0,97 \pm 0,25$ & 0,138 \\
\hline
\end{tabular}




\section{Análise microscópica:}

Análise microcópica subjetiva

Em ambos os grupos (enxerto SID e enxerto pericárdio), nos segmentos distal e proximal ao local enxertado (área referencial) foi observado $100 \%$ de presença de endotélio e de músculo liso. No grupo A regeneração endotelial esteve presente na área do enxerto em $75 \%$ dos casos e no grupo B este valor foi de $62,5 \%$. O colágeno esteve presente em $100 \%$ no local enxertado em ambos os grupos, em $75 \%$ na área referencial do grupo SID e em $100 \%$ do grupo B. O processo inflamatório esteve presente em 100\% no local enxertado tanto no grupo A quanto no B e apenas no grupo do pericárdio observou-se processo inflamatório nas áreas referenciais, isto é, adjacentes ao enxerto (Tabela 2).
Análise microscópica objetiva:

A soma das variáveis nos forneceu o escore do processo inflamatório. Realizando a somatória do grupo A no local enxertado obteve-se 4,75, que caracteriza um processo inflamatório crônico. O grupo B no sítio de implantação de pericárdio bovino igualmente permaneceu na fase inflamatória crônica com escore de 6,12. (Tabela 3)

\section{Análise quantitativa de músculo e colágeno:}

Através da coloração Sirius Red quantificou-se a presença de colágeno e de músculo em ambos os grupos, tanto no enxerto como nas áreas referencial. Para tanto, adotou-se o teste não-paramétrico de Mann-Whitney, considerando-se um valor de $\mathrm{p}<0,05$ estatisticamente

TABELA 2 - Avaliação histológica subjetiva do enxerto de submucosa e de pericárdio bovino implantados na veia cava inferior e em suas áreas adjacentes.

\begin{tabular}{|c|c|c|c|c|c|c|c|}
\hline Variável & Resultado & $\begin{array}{l}\text { ENXERTO } \\
\text { SID }(n=8)\end{array}$ & $\begin{array}{l}\text { Pericárdio } \\
(\mathrm{n}=8)\end{array}$ & $\begin{array}{l}\text { Valor } \\
\text { de p }\end{array}$ & $\begin{array}{l}\text { ÁREA REF } \\
\text { SID }(n=8)\end{array}$ & $\begin{array}{l}\text { ENCIAL } \\
\text { Pericárdio } \\
(\mathrm{n}=8)\end{array}$ & $\begin{array}{l}\text { Valor de } \\
\text { p }\end{array}$ \\
\hline Endotélio & $\begin{array}{l}\text { Presente } \\
\text { Ausente }\end{array}$ & $\begin{array}{l}6 \\
(75,0 \%) \\
2 \\
(25,0 \%)\end{array}$ & $\begin{array}{l}5 \\
(62,5 \%) \\
3 \\
(37,5 \%)\end{array}$ & 1,0000 & $\begin{array}{l}8 \\
(100 \%) \\
0 \\
(0 \%)\end{array}$ & $\begin{array}{l}8 \\
(100 \%) \\
0 \\
(0 \%)\end{array}$ & - \\
\hline Músculo & $\begin{array}{l}\text { Presente } \\
\text { Ausente }\end{array}$ & $\begin{array}{l}5 \\
(62,5 \%) \\
3 \\
(37,5 \%)\end{array}$ & $\begin{array}{l}7 \\
(87,5 \%) \\
1 \\
(12,5 \%)\end{array}$ & 0,5692 & $\begin{array}{l}8 \\
(100 \%) \\
0 \\
(0 \%)\end{array}$ & $\begin{array}{l}8 \\
(100 \%) \\
0 \\
(0 \%)\end{array}$ & - \\
\hline Colágeno & $\begin{array}{l}\text { Presente } \\
\text { Ausente }\end{array}$ & $\begin{array}{l}8 \\
(100 \%) \\
0 \\
(0 \%)\end{array}$ & $\begin{array}{l}8 \\
(100 \%) \\
0 \\
(0 \%)\end{array}$ & - & $\begin{array}{l}6 \\
(75 \%) \\
2 \\
(25 \%)\end{array}$ & $\begin{array}{l}8 \\
(100 \%) \\
0 \\
(0 \%)\end{array}$ & 0,4667 \\
\hline $\begin{array}{l}\text { Processo } \\
\text { inflamatório }\end{array}$ & $\begin{array}{l}\text { Presente } \\
\text { Ausente }\end{array}$ & $\begin{array}{l}8 \\
(100 \%) \\
0 \\
(0 \%)\end{array}$ & $\begin{array}{l}8 \\
(100 \%) \\
0 \\
(0 \%)\end{array}$ & - & $\begin{array}{l}0 \\
(0 \%) \\
8 \\
(100 \%)\end{array}$ & $\begin{array}{l}2 \\
(25 \%) \\
6 \\
(75 \%)\end{array}$ & 0,4667 \\
\hline
\end{tabular}

TABELA 3 - Resultados da análise microscópica objetiva, na qual foram estabelecidos os sinais negativo (-) para o processo inflamatório agudo e o sinal positivo (+) para o processo inflamatório crônico e os escores -9 a 2 para a graduação dos parâmetros do processo inflamatório agudo e os escores +2 a +9 para graduação dos parâmetros do processo inflamatório crônico. A somatória dos escores definiu o processo inflamatório e sua graduação na área do enxerto e nas áreas referenciais tanto para o enxerto de submucosa quanto para o enxerto de pericárdio bovino.

\begin{tabular}{|c|c|c|c|c|c|c|}
\hline \multirow[t]{3}{*}{ Variável } & \multicolumn{2}{|c|}{ ENXERTO } & \multirow{3}{*}{$\begin{array}{c}\text { Valor de } \\
\text { p }\end{array}$} & \multicolumn{2}{|c|}{ ÁREA REFERENCIAL } & \multirow{3}{*}{$\begin{array}{c}\text { Valor de } \\
\text { p }\end{array}$} \\
\hline & $\operatorname{SID}(n=8)$ & $\begin{array}{c}\text { Pericárdio } \\
(\mathrm{n}=8)\end{array}$ & & $\operatorname{SID}(n=8)$ & $\begin{array}{c}\text { Pericárdio } \\
(\mathrm{n}=8)\end{array}$ & \\
\hline & Média \pm DP & Média \pm DP & & Média \pm DP & Média \pm DP & \\
\hline Congestão & $0 \pm 0$ & $0 \pm 0$ & - & $0 \pm 0$ & $0 \pm 0$ & - \\
\hline Edema & $0 \pm 0$ & $0 \pm 0$ & - & $0 \pm 0$ & $0 \pm 0$ & - \\
\hline Neutrófilo & $-1,13 \pm 0,64$ & $-1,13 \pm 0,35$ & 0,9591 & $-0,50 \pm 0,76$ & $-0,75 \pm 0,46$ & 0,3823 \\
\hline Granulação & $1,13 \pm 0,35$ & $1,63 \pm 1,19$ & 0,5737 & $0,25 \pm 0,46$ & $0,50 \pm 0,93$ & 0,8785 \\
\hline Fibrose & $2,13 \pm 0,83$ & $2,88 \pm 0,35$ & 0,0830 & $0,63 \pm 0,74$ & $1,25 \pm 0,71$ & 0,1304 \\
\hline Monócitos & $2,63 \pm 0,74$ & $2,75 \pm 0,46$ & 0,9591 & $1,13 \pm 0,35$ & $1,25 \pm 0,71$ & 0,6454 \\
\hline Soma & $4,75 \pm 1,49$ & $6,13 \pm 1,25$ & 0,1049 & $1,50 \pm 1,20$ & $2,25 \pm 1,75$ & 0,3282 \\
\hline
\end{tabular}


significante. O grupo A, no local enxertado, apresentou $74,67 \%$ de músculo e $25,40 \%$ de colágeno. Já no grupo B, na mesma região, demonstrou 32,93\% de colágeno e 67,08\% de músculo. A musculatura lisa esteve presente em 85,22\% da área referencial do grupo A, e em 86,58\% do grupo B. Já o colágeno esteve presente em 14,80\%do grupo A e em 13,42\% do grupo B, nas mesmas áreas. (Figura 3). Desta forma, podemos dizer que não foram encontradas diferenças significativas entre as duas estruturas de enxerto (SID e pericárdio bovino), em relação ao percentual de músculo e percentual de colágeno, tanto no local do enxerto como na área referencial (laterais ao enxerto).

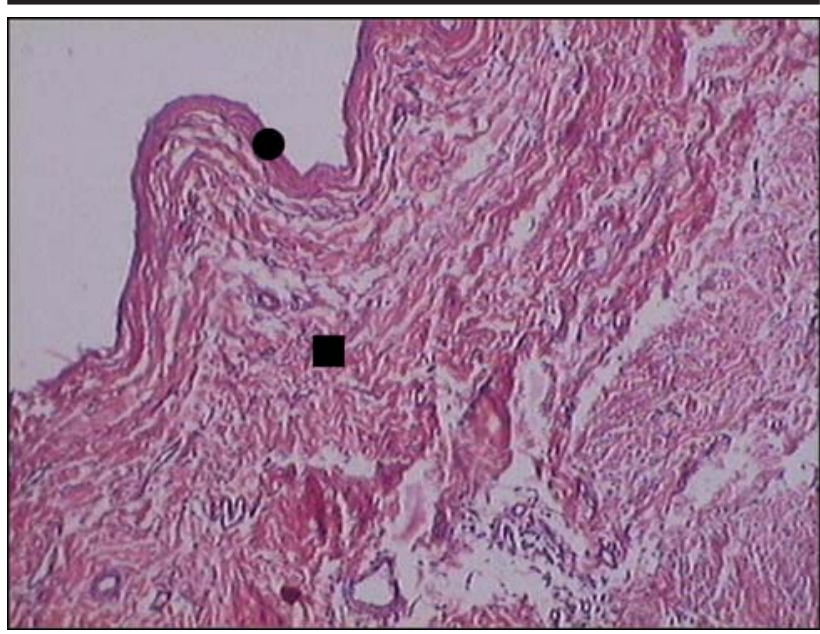

FIGURA 2 - Fotomicrografia de corte histológico de veia cava corado com hematoxilina eosina, no local onde foi implantada a submucosa de intestino delgado. Observa-se a neoproliferação epitelial (๑) e muscular (ם)

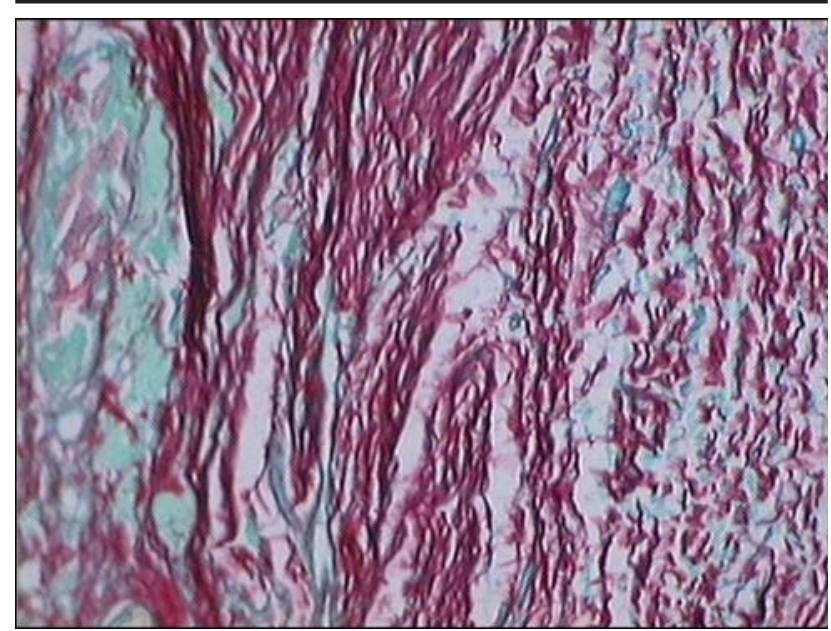

FIGURA 3 - Fotomicrografia de corte histológico de veia cava corado com "sirius red", no local onde foi implantada a submucosa de intestino delgado. Observa-se em verde as fibras de colágeno e em vermelho neoproliferação muscular.

\section{Discussão}

O uso de bioenxertos no sistema arterial e venoso não é novidade, uma vez que o uso de intestino invertido já havia sido preconizado por Matsumoto em 1966 como substituto de grandes veias no cão. A baixa velocidade de fluxo e a baixa pressão venosa são responsáveis pela trombose precoce das veias. Nas artérias, por outro lado, a dilatação aneurismática e a trombose são as maiores causas de insucesso dos enxertos arteriais. A submucosa de intestino delgado em estudos realizados tanto em artérias quanto em veias demonstrou ser um excelente bioenxerto uma vez que apresenta baixa trombogenicidade, proporciona uma rápida endotelização, graças talvez a rápida neovascularização, observada 2 a 4 dias após a implantação do enxerto e baixos índices de estenose ${ }^{1}$. Segundo Lantz ${ }^{1}$,ao contrário das artérias, o implante de submucosa nas veias é capaz de induzir uma diminuta regeneração muscular e induzir o aparecimento de uma menor quantidade de fibras elásticas. Segundo o autor este fenômeno é conseqüência da adaptação do tecido ao estresse a que ele é submetido ${ }^{1}$. Em nosso estudo utilizamos apenas um patch de SID e de pericárdio bovino, o que difere de outros estudos relatados na literatura, em que foi usado um enxerto para substituir uma porção de veia. No $30^{\circ}$ dia de pós-operatório, quando os animais foram submetidos ao estudo ultrassonográfico, evidenciamos estenose da veia cava em 1 animal do grupo com enxerto de submucosa e em 2 animais com enxerto de pericárdio. Após o sacrifício, a estenose da veia cava inferior só foi constatada em 2 animais do grupo A (submucosa) e em 3 animais do grupo B (pericárdio). Sendo a ultra-sonografia um exame que depende não só da experiência do executante como também das condições anatômicas locais, acreditamos que o aspecto subjetivo possa explicar o número maior de estenoses que verificamos após o sacrifício dos animais. De qualquer maneira ao compararmos o grupo A com o B verificamos que não houve diferenças estatisticamente significantes quanto a esse parâmetro. Em 40 dias após a implantação, não constatamos a presença de trombos nos locais de enxerto em nenhum dos animais do grupo A e em apenas 1 animal do grupo B. A retração do enxerto e a calcificação, relatados na literatura no que concerne ao emprego do pericárdio bovino, não foi evidenciada em nenhum dos animais desse grupo, tampouco nos animais com enxertos de submucosa. . Acreditamos que esse fenômeno biológico seja mais evidente a longo prazo, certamente num período maior que 40 dias. Quanto a avaliação microscópica, observamos uma completa endotelização do retalho de submucosa em 75\% dos casos e em $62,5 \%$ dos casos de pericárdio bovino. No subendotétio da área enxertada observou-se músculo , colágeno organizado do tipo maduro e uma rede de neo-vasos. Ass fibras musculares lisas não estiveram presentes em todos os enxertos, tanto de pericárdio bovino (87,5\%) quanto de SID $(62,5 \%)$. No entanto quando presente elas representaram 74,67\% da área enxertada com submucosa porcina e $67 \%$ da área enxertada com pericárdio bovino. $\mathrm{O}$ colágeno maduro esteve presente em 25,4\% dos casos com submucosa e em 33\% dos casos com pericárdio bovino. Infelizmente não pudemos comparar o grau de proliferação de células musculares lisas da veia cava inferior em relação aos enxertos implantados nas artérias . Todavia convém salientar que tanto no enxerto de submucosa quanto de pericárdio houve uma proliferação importante de músculo, o que de certa forma contrasta com os achados de Lantz ${ }^{1}$. 
A avaliação do processo inflamatório nos dois enxertos caracterizou-se por um processo inflamatório do tipo crônico e moderado e não houve diferença estatisticamente significante. Esse estudo demonstrou e comprovou os excelentes resultados relatados na literatura ${ }^{1,2,4,5}$ quanto ao emprego da submucosa de intestino delgado porcino como enxerto vascular, todavia esses resultados não diferiram daqueles observados com o pericárdio bovino. A literatura apresenta estudos comparativos de enxerto de submucosa de intestino delgado com enxertos de veia safena ou com próteses de PTFE, exclusivamente em artérias $^{4,5}$ Esse estudo é inédito no que concerne a veias e a comparação com o pericárdio bovino, o que de certa forma não nos permitiu maiores discussões. Existe claramente uma tendência do enxerto de submucosa apresentar melhores resultados que o de pericárdio bovino. Um número mais expressivo de animais e um tempo de observação mais longo talvez permitisse uma conclusão mais realista.

\section{Conclusão}

Um retalho de submucosa de intestino delgado porcino mostrou ser um excelente substrato para a regeneração vascular quando implantado em veia cava inferior, contudo os resultados encontrados não diferem daqueles observados com o uso de pericárdio bovino .

\section{Agradecimentos}

Agradecemos a professora Márcia Olandoski por sua valiosa colaboração nas análises estatísticas.

\section{Referências}

1. Lantz GD, Badylak SF, Coffey AC, Geddes LA, Sandusky GE. Small intestinal submucosa as a superior vena cava graft in the dog. J Surg Res. 1990; 53:175-81.

2. Robotin-Johnson, MC, Swanson PE, Johnson DC, Schuessler RB, Cox JL. An experimental model of small intestinal submucosa as a growing vascular graft. J Thorac Cardiovasc Surg. 1992;116(5):805-11.

3. Roeder AS, Lantz GC, Geddes LA. Mechanical remodeling of small-intestine submucosa small-diameter vascular grafts: apreliminar report. Biomed Instrum Technol. 2001;
35:110-20.

4. Sanduski GE, Badylak SF, Morff RJ, Johnson WD, Lantz GC. Histologic findings after in vivo placement of small intestine submucosal vascular grafts and saphenous vein grafts in the carotid artery in dogs. Am J Pathol. 1992; 42 : 317-324.

5. Sanduski GE, Badylak SF, Lantz GC. Healing comparison of small intestine submucosa and PTFE grafts in canine carotid artery. J Surg Res. 1995;58:415-20.

6. Pires AD, Saporito WF, Leão LEV, Forte V, Cardoso SH. Pericárdio bovino utilizado como remendo no sistema cardiovascular. Rev Bras Cir Cardiovasc. 1997; 12(2) ; 176-87.

7. Schmidt CE , Baier JM. Acellular vascular tissue : natural biomaterials for tissue repair and tissue engineering. Biomaterials. 2000;21 : 2215-31.

8. Senior K. Intestinal collagen shows promice as a smallvessel graft. Lancet. 1999; 345:1533.

9. Hodde JP, Badylak SF, Brightman AO. Glycosaminoglycan content of small intestine submucosa: A bioscaffold for tissue replacement. Tissue Engineering. 1996; 2:209-17, 1996.

10. Grimsley BR, Wells JK, Pearl GJ, Garret WV. Bovine pericardial patch angioplasty in carotid endarterectomy. Am Surg. 2001; 67: 890-5.

11. Agerberth B , Lee J-Y, Bergman T. Amino acid sequence of PR-39: isolation from pig intestine of a new member of the family proline-arginine-rich antibacterial peptides. Eur J Biochem. 1991;202:849-54.

12. Badylak SF, Kropp B, Mcpherson T, Liang H, Snyder PW. Small intestine submucosa: a rapidly resorbed bioscaffold for augmentation cytoplasty in a dog model. Tissue Engineering 1998; 4: 379-87.

13. Badylak SF, Lantz GC, Coffey A, Geddes LA. Small intestinal submucosa as a large diameter vascular graft in the dog. J Surg Res. 1989; 47:74-8.

14. Badylak SF, Lantz GC, Coffey A, Geddes LA. Comparison of the resistence to infection of intestinal mucosa arterial autografts versus polytetrafluoretilene arterial protheses in a dog model. J Vasc Surg. 1994; 19 :465-72.

15. Bandylak SF, Tullis R, Kokini K. The use of xenogeneic small intestine submucosa as a biomaterial for Achilelles tendon repair in a dog model. J Biomed Mater Res. 1995; 29:977-85.

\section{Correspondência}

Fernando Hintz Greca

Av. Visconde de Guarapuava 5087/1401

80.240 - 010 - Curitiba - PR

fernando.greca@bbs2.sul.com.br
Conflito de interesse: nenhum Fonte de financiamento: nenhuma

Recebimento: 02/03/2005

Revisão: 04/04/2005

Aprovação: 03/05/2005

\section{Como citar este artigo:}

Greca FH, Noronha L, Costa FDA, Souza Filho ZA, Soccol AT, Feres AN, Duda JR, Adams E. Estudo comparativo da biocompatibilidade da submucosa intestinal porcina e pericárdio bovino usados como enxertos na veia cava de cães. Acta Cir Bras. 2005 [periódico na internet] Jul-Ago;20(4). Disponível em URL: http://www.scielo.br/acb

* Figuras coloridas disponíveis em http://www.scielo.br/acb 